\title{
Comparison Between Wells' Criteria and Khorana Score in Detecting Asymptomatic Deep Vein Thrombosis in Colorectal Cancer Patients in Dr. Hasan Sadikin Hospital \\ Teguh Marfen Djajakusumah, ${ }^{1, *}$ Putie Hapsari, ${ }^{1}$ Daniel Marthin Situmorang, ${ }^{1}$ Muhammad Faiz Ulurrosyad
}

Background: Deep vein thrombosis is a blood clot that occurs in the deep veins. Fifty percent of patients with deep vein thrombosis do not show clinical symptoms. The incidence of deep vein thrombosis in colorectal cancer patients is higher than in other cancer patients. Several scoring system models, such as Wells' criteria and Khorana score, were developed to help

Methods: This study was a prospective observational analytic with cross sectional design that compared the Khorana score with Wells' criteria in predicting the occurrrence of asymptomatic deep vein thrombosis in colorectal cancer patients. Comparisons were made using Chi Square analytical test and diagnostic tests.

Results: A total of 63 patients were obtained. Using Wells' criteria, 55 patients $(87.3 \%)$ fell into the mild risk category, 8 patients $(12.7 \%)$ in the moderate risk category and no patients in the high risk category. Using Khorana score, 35 patients (55.6\%) fell into the mild risk category, 28 (44.4\%) patients in the moderate risk category, and no high risk category patients were found. There were 14 patients $(22.2 \%)$ with asymptomatic deep vein thrombosis and 49 patients $(77.8 \%)$ without deep vein thrombosis. Comparison of the proportion of Wells' criteria with asymptomatic patients has a $p$-value of 0.48 , while Khorana score with asymptomatic patients has a $p$-value of 0.001 .

Conclusion: Khorana score is better than Wells' criteria in detecting asymptomatic deep vein thrombosis in colorectal cancer patients.

Keywords: Wells score, Khorana score, asymptomatic DVT, colorectal cancer https://doi.org/10.36864/jinasvs.2021.1.006

*Correspondence: marfen.djajakusumah@gmail.com, +628122023770

${ }^{1}$ M.D., Vascular and Endovascular Division, Department of Surgery, Dr. Hasan Sadikin Hospital - Faculty of Medicine, Universitas Padjadjaran, Bandung, Indonesia

\section{INTRODUCTION}

Thrombosis in the clotting of blood in the cardiovascular system, including in deep veins. ${ }^{1,2}$ Disrupted blood flow in the vein is the principal cause of DVT. ${ }^{3,4}$ Fifty percent of patients with DVT present asymptomatically. Mortality rate of DVT is $5-8 \%$ due to complications such as pulmonary embolism. ${ }^{5}$

Cancer is the most predominant risk factor in DVT development. Risk of DVT increases up to six times in cancer patients. ${ }^{6}$ DVT is found in fifty percent of cancer patients during autopsy. The increased risk is due to chemotherapy and hormonal therapy that may incite the development of DVT. Intravenous line insertion may also play a role in thrombus formation. ${ }^{7}$ In Europe, colorectal cancer patients have the highest risk of developing DVT compared to other cancer. ${ }^{8}$

Several scoring systems have been developed to help quickly and easily diagnose DVT. The most widely used scoring systems are Khorana score and Wells' criteria. ${ }^{6,8}$ Khorana score is a predictive scoring system. ${ }^{5}$ This scoring system is utilized in developed countries to determine cancer patients that will receive prophylaxis. ${ }^{9}$ Wells' Criteria may help diagnose DVT through clinical examinations. However, a third of DVT patients present without distinctive clinical features. ${ }^{7}$ The effectiveness of Wells' criteria application in cancer patients has not been reported. ${ }^{9}$

There's currently no study that compares Khorana score and Wells' criteria in detecting asymptomatic DVT. Therefore, we see it necessary to conduct a study to determine the most optimal scoring system to detect asymptomatic DVT in colorectal patients.

\section{METHOD}

This study is a cross-sectional analytical study. Data are collected from colorectal cancer outpatients in Dr. Hasan Sadikin Hospital during the period of December 2017 - October 2018 that has not been diagnosed with DVT. Khorana score and Wells' criteria are then evaluated on the patients. The patients are then examined using compression ultrasound to diagnose DVT. 
Table 1. Characteristics of the patients

\begin{tabular}{lc}
\hline \multicolumn{1}{c}{ Variable } & $\mathbf{N}=\mathbf{6 3}$ \\
\hline Age (year) & \\
Mean \pm Std & $48,9 \pm 12,32$ \\
Median & 49 \\
Range (min-max) & $16-78$ \\
Sex & \\
Male & $33(52,4 \%)$ \\
Female & $30(47,6 \%)$ \\
Khorana score & \\
Low risk & $35(55,6 \%)$ \\
Moderate risk & $28(44,4 \%)$ \\
High risk & $0(0 \%)$ \\
Wells' criteria & \\
Low risk & $55(87,3 \%)$ \\
Moderate risk & $8(12,7 \%)$ \\
High risk & 0 \\
Asymptomatic DVT & $14(22,2 \%)$ \\
Yes & $49(77,8 \%)$ \\
No &
\end{tabular}

Characteristics of patients such as age, sex, and location of colorectal cancer are analyzed. Data from each scoring systems are compared with the results from ultrasound examination using Chi-square analytical test. Diagnostic test, such as sensitivity, specificity, negative predictive value (NPV), positive predictive value (PPV), and accuracy are also performed.

\section{RESULTS}

We found 63 colorectal cancer outpatients that satisfied the sample criteria. We found that most patients fall into the low-risk category when evaluated using both Wells' criteria and Khorana score. No patients fall into the high-risk category in both scoring systems. Using ultrasound, we discovered that 14 patients have asymptomatic DVT. Characteristics of the patients, as well as the results of each scoring systems and ultrasound examination are presented in table 1.

Analytical test on the Khorana criteria proportion yields a $p$-value of 0.001 . Results of diagnostic tests show a sensitivity of $100 \%$ (very strong), specificity of $71.4 \%$ (moderate), PPV of $50 \%$ (very weak), NPV of $100 \%$ (very strong), and accuracy of $77.8 \%$ (moderate). See table 2 .

Analytical test on the Wells' criteria proportion yields a $p$-value $>0.05(p$-value $=0.48)$. Results of diagnostic tests shows a sensitivity of $7.1 \%$ (very weak), specificity of $85.7 \%$ (strong), PPV of $12.5 \%$ (very weak), NPV of $76.4 \%$ (moderate), and accuracy of $68.3 \%$ (weak). See table 3.

\section{DISCUSSION}

Table 2. Comparison of proportion for Khorana score

\begin{tabular}{lcc}
\hline \multirow{2}{*}{ Variable } & \multicolumn{2}{c}{ Asymptomatic DVT } \\
\cline { 2 - 3 } & $\begin{array}{cc}\text { Yes } \\
\mathbf{N = 1 7}\end{array}$ & $\mathbf{N o}$ \\
& & \\
\hline Khorana score & $0(0 \%)$ & $35(71.4 \%)$ \\
Low risk & $14(100 \%)$ & $14(28.6 \%)$ \\
Moderate risk & & \\
\hline
\end{tabular}

Table 3. Comparison of proportion for Wells' criteria

\begin{tabular}{lcc}
\hline \multirow{2}{*}{ Variable } & \multicolumn{2}{c}{ Asymptomatic DVT } \\
\cline { 2 - 3 } & Yes & No \\
& $\mathbf{N = 1 3}$ & $\mathbf{N = 1 7}$ \\
\hline Wells criteria & $13(92.9 \%)$ & $42(85.7 \%)$ \\
Low risk & $1(7.1 \%)$ & $7(14.3 \%)$ \\
Moderate risk & \\
\hline
\end{tabular}

Table 1 shows the distribution of Wells' criteria, Khorana score, and ultrasound results. Characteristically, this study is in line with available literatures in which age is the most dominant risk factor in the incidence of colorectal cancer. Incidence rate rises in patients above 40 -year-old. In this study, $90 \%$ of the patients are diagnosed at age 50 and above. ${ }^{10,11}$ The risk of colorectal cancer is lower in women compared to men. ${ }^{12}$

The analytical test performed on the Wells' criteria proportion shows an insignificant result with weak diagnostic tests result. Therefore, we can conclude that there is no correlation between Wells' score's cut off point with positive ultrasound result. On the other hand, Chi-square test comparing the proportion of Khorana score with asymptomatic DVT yields a statistically significant result. From this result, we can concur that there is a correlation between Khorana score's cut off point with asymptomatic DVT. Based in the diagnostic tests, Khorana score is more sensitive compared to ultrasound in diagnosing asymptomatic DVT but is less specific. ${ }^{13}$

\section{CONCLUSION}

In conclusion, Khorana score is more accordant with the incidence of asymptomatic DVT and therefore is better in detecting asymptomatic DVT in colorectal patients compared to Wells' criteria.

\section{CONFLICT OF INTEREST}

The author states the original work, and there is no conflict of interest in doing this research.

\section{ORCID ID OF AUTHORS}

Teguh Marfen Djajakusumah

https://orcid.org/0000-0001-6114-2406

Putie Hapsari

https://orcid.org/0000-0002-9310-4524

Daniel Marthin Situmorang

https://orcid.org/0000-0003-1309-7844

Muhammad Faiz Ulurrosyad

https://orcid.org/0000-0002-0098-4092 


\section{REFERENCES}

1. Malone PC, Agutter PS. The Aetiology of Deep Venous Thrombosis: A Critical, Historical and Epistemological Survey. Dordrecht: Springer Netherlands; 2008.

2. Hirsh J and Hoak J. Management of Deep Vein Thrombosis and Pulmonary Embolism. Circulations. 2006;93:2212-2245.

3. Skinner N, Mochan P. Deep Vein Thrombosis (DVT), Case Management Adherence Guideline. Case Management Society of America. 2007;1:3.

4. Prandoni P. Prevention and Treatment of Venous Thromboembolism with Low Molecular-Weight Heparins: Clinical Implication of Recent European Guidelines. Thrombosis Journal Vol. 6. Thromboembolism Unit University of Purdue. Italy. 2008;5:1-5.

5. Bulger CM, Jacobs C, Patel NH. Epidemiology of acute deep vein thrombosis. Tech Vasc Interv Radiol. 2004 Jun;7(2):50-4.

6. Gloviczki P. Handbook of Venous Disorder. Guidelines of The American Venous Forum. 2010.

7. Falanga A, Zacharski L. Deep vein thrombosis in cancer: the scale of the problem and approaches to management. Ann Oncol Off J Eur Soc Med Oncol. 2005 May;16(5):696-701.

8. Ay $C$, Dunkler $D$, Marosi $C$, Chiriac $A$, Vormittag $R$, Simanek $R$, et al. Prediction of venous thromboembolism in cancer patients. 2010;116(24):5377-82.

9. Khalil J, Bensaid B, Elkacemi $\mathrm{H}$, et al. Venous thromboembolism in cancer patients : an underestimated major health problem. World J Surg Oncol. 2015;1-17.

10. Brunicardi F, Andersen D, Billiar T, et al. Schwartz's Principles of Surgery $11^{\text {th }}$ Edition. Mcgraw Hill. $2015 ; 10$.

11. Haggar FA, Boushey RP, Ph D. Colorectal Cancer Epidemiology: Incidence, Mortality, Survival, and Risk Factors. 2009;6(212):191-7.

12. Perhimpunan Dokter Spesialis Bedah Digestif Indonesia. Panduan Penatalaksanaan Kanker Kolorektal. 2017.

13. Goldhaber SZ, Bounameaux H. Pulmonary embolism and deep vein thrombosis. Lancet (London, England). 2012 May;379(9828):1835-46. 